\title{
Avaliação de softwares educativos para o ensino de língua Portuguesa
}

\author{
Evaluation of educational software for teaching Portuguese
}

\author{
Rozelma Soares de França \\ Universidade Federal de Pernambuco \\ Centro de Informática \\ Recife - PE \\ rsf2@cin.ufpe.br
}

\author{
Ana Cristina Barbosa da Silva \\ Universidade Federal de Pernambuco \\ Centro Acadêmico do Agreste \\ Caruaru - PE \\ kristtinna@bol.com.br
}

Resumo Esta pesquisa teve como objetivo avaliar dois softwares educativos de conteúdos específicos de
Língua Portuguesa, em discos compactos, para averiguar a possibilidade pedagógica desses
materiais. A análise se baseou em critérios para os aspectos técnico, pedagógico, de leitura e
compreensão textual. Após as análises, verificou-se que ambos os softwares não apresentam
características que propiciam um eficiente ensino, pois apresentam boas características na
parte técnica, mas nas dimensóes pedagógica e específica não apresentam boa qualidade, tendo
um dos softwares, apenas característica lúdica.

Palavras-Chave: Avaliação de software educativo, disco compacto, língua portuguesa.

\begin{abstract}
This research aimed at evaluating two Portuguese Language content educational software on compact discs in order to determine the pedagogical potential of those materials. The analysis was based on criteria for the technical, pedagogical, reading comprehension and textual aspects. After the analysis, it was found that both software do not present features that deliver effective learning because even though they have good technical features, the pedagogical and specific dimensions do not show good quality, and one of the software proposes only playful features.
\end{abstract}

Keywords: Evaluation of educational software, compact disc, Portuguese. 


\section{Introdução}

Na sociedade contemporânea percebe-se que as tecnologias de informação e comunicação estão cada vez mais presentes nas atividades humanas, sendo a escola um dos ambientes que possibilitam a aproximação do indivíduo a essa tecnologia. Nesta perspectiva, o computador vem ganhando gradativamente espaço em âmbito escolar como instrumento para auxílio nos processos de ensino e aprendizagem, o que vai requerer da principal agência de letramento a exploração efetiva dos meios digitais aportados no computador e a reflexão a cerca do novo letramento - letramento digital, que consiste, segundo Soares [16], em um "estado ou condição que adquirem os que se apropriam da nova tecnologia digital e exercem práticas de leitura e de escrita na tela, diferente do estado ou condição - do letramento - dos que exercem práticas de leitura e de escrita no papel".

Neste contexto, os softwares educativos se constituem num importante instrumento para difusão do saber e devem incorporar não apenas mecanismos hipermidiáticos, como também possuir qualidade pedagógica no momento da "transposição didática" [3]. Em paralelo à busca, há um crescente aumento no desenvolvimento de softwares educativos, que, em sua maioria, são construídos com um fim exclusivamente comercial [3]. Assim, torna-se imprescindível avaliar a qualidade desses materiais na tentativa de selecionar aqueles que melhor possam contribuir para a aquisição de conhecimentos relativos aos conteúdos pedagógicos.

Neste sentido, esta pesquisa vem expor os resultados da análise de dois softwares educativos de Língua Portuguesa, em discos compactos, destinados às séries finais do ensino fundamental, cujo objetivo foi averiguar a possibilidade pedagógica desses materiais, segundo critérios propostos por Silva et al. [13], uma vez que estes, além de contemplarem os aspectos técnicos e pedagógicos como apontam outros autores $[1,7,18,19]$ também trazem em cena a importância de se avaliar e discutir acerca dos conteúdos específicos de uma dada disciplina curricular, no caso, de Língua Portuguesa. O enfoque deste estudo foi a abordagem sobre a leitura e a compreensão textual, que, no momento atual, ganharam um novo suporte, saindo do impresso e se apresentando também no meio digital.

\section{Tecendo a leitura no ambiente digi- tal}

Ainda há, em nossas escolas, segundo Silva [12], fortes traços do típico ensino da leitura caracterizado pelo movimento mecanizado que é executado da mesma ma- neira ano após ano que, quase sempre, é teatralizado nos palcos da ilusão, onde os atores apenas fingem que leem para contentar a instituição. Apesar disso, muitas práticas pedagógicas sobre a leitura têm sido modificadas, pois a sociedade do conhecimento exige outro olhar e novas atitudes dos indivíduos que dela fazem parte para que possam começar a andar a passos largos rumo à proficiência e autonomia na prática leitora. Isso implica em parar de ler para memorizar normas gramaticais e a passos largos começar a ler para enxergar melhor o mundo, compreendendo nossa sociedade criticamente e descobrindo os porquês dos diferentes aspectos da vida, o que significa ancorar-se

numa concepção de leitura que não a veja como simples resposta passiva e mecânica, bem à moda behaviorista, mas, a passos largos, considere-a enquanto um processo dinamizador da produção de sentidos por um grupo de pessoas, enquanto transação ou interação entre leitor e diferentes tipos de texto. A passos largos, é preciso que se saiba traduzir essa concepção da leitura em programas significativos de ensino, que resultem na transformação, na emancipação, na libertação dos leitores [12].

Os Parâmetros Curriculares Nacionais (PCN) de Língua Portuguesa [2] insistem sobre a necessidade da escola formar leitores e escritores, no sentido de produtores textuais, e alerta para que os educadores procurem ultrapassar os limites estreitos de práticas exclusivamente escolares, proporcionando aos estudantes o conhecimento e compartilhamento da diversidade textual que circula na sociedade [10]. Assim, de acordo com Santos et al. [9], é requerido da escola, considerada a principal agência de letramento, que promova e amplie num processo gradual e ininterrupto, a "apropriação de saberes, de construção de conhecimentos, sobre e nas práticas em que os gêneros se inserem".

Segundo Freitas [4] e Kleiman [5], para se desvencilhar de práticas excludentes é necessário o convívio com textos, leitores e escritores verdadeiros e com situações de comunicação que os tornem necessários. Nesta perspectiva, há uma quebra da concepção de ensino tradicional de língua materna e é incorporada uma perspectiva que se inspira no sociointeracionismo "cujos enfoques teóricos dirigem o ensino da língua(gem) para seu uso e funcionamento discursivo, enquanto sistema semiótico e simbólico, contextualizado e determinado sóciohistoricamente" [4].

Vivendo em uma sociedade de informação e rede, nota-se que as habilidades e letramento do impresso são essenciais, mas não suficientes para dar assistência aos indivíduos da era digital, incluindo o ciberespaço. Com 
isso, os "educadores de letramento" assumem a responsabilidade de proporcionar aos sujeitos oportunidades cautelosamente planejadas para que eles aprendam como se tornar navegadores críticos no novo panorama do letramento em tempos digitais [15]. Assim, diante desse novo cenário, percebe-se a necessidade de desenvolver habilidades leitoras para o mundo digital, ampliando possibilidades, passando a incluir representações gráficas, visuais e sonoras nas práticas educativas. Desse modo, a escola é cada vez mais "chamada a responder aos desafios impostos pelo novo letramento, preparando alunos capazes de ler, escrever e navegar no espaço cibernético, correspondendo, assim, às necessidades dessas novas tecnologias" [17].

$\mathrm{O}$ acesso à Internet tem favorecido a crescente participação de pessoas, dos mais variados níveis escolares e socioeconômicos, em diferentes interações mediadas por hipertextos, estes definidos como uma organização nãolinear que reúne informações verbais, visuais e sonoras e que permite uma leitura totalmente singular e multissemiótica e a possibilidade de acesso rápido a uma infinidade de textos, na qual o leitor pode interagir com o autor e/ou modificar o texto $[6,8]$.

Tendo a Internet e os softwares educativos, dentre outros meios digitais, como ferramentas para promoção do saber na sociedade do conhecimento, cabe à escola explorar efetivamente, de modo mais significativo, tais recursos e refletir acerca do novo letramento - letramento digital - demandado pelas diversas práticas de linguagem ambientadas no computador. Assim, segundo Tavares [17], o modelo de instrução de leitura a ser usado para atingir os objetivos do novo letramento deverá ter como base uma proposta que defenda a construção do conhecimento pela solução de problemas e interação verbal, onde o professor ocupará a posição de mediador entre o aluno e o novo, no caso da leitura, entre o aluno e o hipertexto, enquanto que os discentes assumirão a postura de produtores de conhecimento de modo geral e dos conhecimentos discursivos, quando se referir à linguagem. Essa proposta

possibilita a liberdade de acesso a diversas fontes de pesquisa, facilitado pelo uso da Internet, libertando o aluno do livro-texto, como única fonte de conhecimento, e criando a necessidade de selecionar, avaliar e usar informações obtidas de forma a solucionar os problemas propostos pelo professor. Além disso, ela incentiva o trabalho colaborativo e a comunicação entre os aprendizes, por defender que a construção do conhecimento se dá pela interação social [17].

Diante do exposto, entende-se que, nos dias atuais, é urgente e fundamental refletir e discutir sobre as transformações ocasionadas pelo ambiente digital, no que concerne às questões relacionadas às práticas de leitura e produção textual, principalmente no contexto escolar, uma vez que essas práticas, viabilizadas pelo hipertexto, trazem a percepção de que ler e escrever são atividades dinâmicas onde o conhecimento vai se construindo como "potência geradora" [11], perspectiva que também se encaixa na leitura e na escritura do ambiente impresso.

Destacando a importância do uso de recursos computacionais no ensino, como mencionado, os softwares educativos se constituem num importante instrumento para difusão do saber e, quando desenvolvidos considerando estratégias de ensino e de aprendizagem bem definidas, eles podem dinamizar e viabilizar o ensino, diferentemente do padrão de escola sistemática e estática, permitindo que o aluno desenvolva seu potencial, respeitando seu ritmo individual e estimulando o aprendizado de maneira adequada.

\section{Avaliação de softwares educativos}

Mesmo sabendo que não há unanimidade na conceituação e utilização da nomenclatura, nesta pesquisa, considerar-se-á a visão de Oliveira et al. [7] que entendem ser software educativo (SE) o programa cujo objetivo é o de favorecer os processos de ensino e aprendizagem, uma vez que são desenvolvidos com a finalidade de levar o estudante a construir determinado conhecimento relativo a um conteúdo didático. Desta forma, o SE corresponde a um

dispositivo digital, planejado e elaborado para fins didáticos/pedagógicos, mediador de conteúdos curriculares da esfera escolar e viabilizador do processo de ensino e de aprendizagem, que requer a mediação do professor da área para seu uso eficiente. Trata-se de um instrumento imbuído de linguagem e aportado no ambiente digital, desta forma, tem especificidades peculiares em detrimento dos materiais do ambiente impresso [14].

Esses materiais podem incorporar textos, sons, imagens e cores fazendo do aprender uma tarefa dinâmica e divertida na qual podem ser explorados os estímulos visuais e auditivos, movimentos e conteúdos das disciplinas escolares [3].

Conforme mencionado em Silva et al. [13] há na literatura alguns modelos de avaliação de software educativo, que contemplam as características técnicas, e que tratam de maneira superficial a questão pedagógica, não havendo ainda a preocupação com a parte específica da 
disciplina. Por esta razão, houve a preocupação de analisar softwares educativos considerando os critérios propostos pelos autores supracitados, critérios estes que estão distribuídos em três categorias:

(i) Técnica: enfoque na instrução de utilização do SE, na compatibilidade de sistema operacional e facilidade de instalação. Contempla ainda a questão da facilidade de acesso a todas as partes que compõem o software, o fornecimento de feedback imediato das ações do usuário, a anulação, interrupção e retomada de tarefa, a refacção das atividades com explicação para correção, se há fornecimento da solução após longa persistência do erro, além de averiguar a existência de textos verbais e hipermodais com a utilização de ferramentas interativas como links, ícones e botões.

(ii) Pedagógica: observa a disponibilidade de material/instrumento para auxiliar o docente na utilização do software, bem como a presença de informações sobre os fundamentos e objetivos pedagógicos do aplicativo. Avalia a coerência do conteúdo em relação à proposta pedagógica apresentada, se o conteúdo é atualizado em relação às teorias da área, se é adequado ao público alvo com diferentes graus de complexidade e se dá ênfase a uma disciplina, porém numa abordagem interdisciplinar. Também são observados a presença de recursos motivacionais e de feedback encorajador, se o software favorece a interpretação sobre os erros e acertos, se registra o desempenho do usuário e se favorece trabalho em grupo.

(iii) Leitura e Compreensão: verifica a presença de textos verbais e não verbais para identificação de informações, contemplando uma reflexão crítica de leitura e busca de outras leituras sobre a mesma temática; se há trabalho de reconhecimento das características do gênero textual, identificação da finalidade do texto e de indicadores das condições do locutor e do interlocutor do texto, remissões a outros textos ou autores e posição do autor, identificação das características do tipo textual, do tema central do texto, de ideias principais e secundárias e a localização de informações explícitas e implícitas; se há atividades de reconhecimento de sentido e efeito de sentido de palavras e expressões em geral e de marcas da oralidade, adequação de usos dialetais e de registro, elementos de humor e ironia, das relações entre partes do texto para promover a coesão e a coerência e a realização de reflexões linguísticas contextualizadas.

A ficha para análise de SE contendo os critérios propostos por Silva et al. [13] dispõe de um espaço para comentários permitindo uma avaliação qualitativa do material, complementando, também, informações da parte quantitativa. Além disso, há uma escala de valores para que o avaliador assinale uma opção de percentual relativa a cada critério: 0 quando não houver nenhuma ocorrência do critério no software; 1 quando se verificar a ocorrência entre $1 \%$ e $35 \% ; 2$ quando se observar que o critério ocorreu entre $36 \%$ e $70 \% ; 3$ quando se perceber que a ocorrência do critério foi entre $71 \%$ e $100 \%$ e NA (não se aplica) quando o critério não se aplicar ao software em análise.

\section{Analisando softwares educativos em disco compacto}

Para fins de emprego dos critérios de avaliação, foram escolhidos os softwares $O$ que vem a seguir? e Educandus 2010. O primeiro dá ênfase à disciplina de Língua Portuguesa e pode ser utilizado com estudantes do ensino fundamental, enquanto que o segundo especifica que seu público-alvo é o Ensino Fundamental II. Ambos os softwares contemplam atividades de leitura e compreensão textual, características consideradas para que os softwares servissem de corpora nesta pesquisa. As exposições das análises seguirão a seguinte ordem: técnica, pedagógica e leitura e compreensão.

\subsection{O que vem a seguir?}

O software $O$ que vem a seguir? visa à prática da leitura e da compreensão textual elaborando hipóteses sobre o que está por vir no texto e, a partir deste, refletir a pertinência de certas suposições para responder a questões colocadas no exercício, por meio de alternativas.

Logo no início (Figura 1), um menu de opções oferece as seguintes possibilidades de navegação: Jogar e Saiba Mais. Ao clicar na primeira opção o usuário é conduzido às narrativas que compõem esse aplicativo educativo. Optando por clicar no segundo link, este apontará para uma página onde estarão explicitadas informações sobre as atividades presentes no SE e a forma como serão trabalhadas. Sua tela inicial contém ainda um ícone para habilitar/desabilitar a reprodução de som.

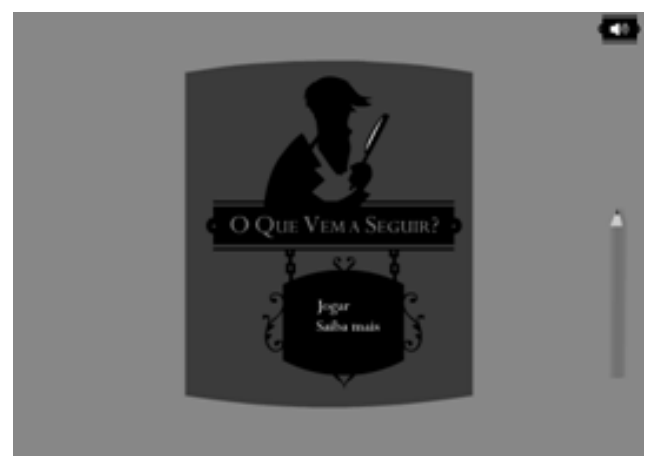

Figura 1: Tela Inicial do software O que vem a seguir? 
Esse software contém quatro textos dos quais foram selecionados para análise apenas dois deles: "A mentira" e "Caso de secretária". Esta escolha se deu pelo fato de contemplarem atividades com o perfil da pesquisa e para delimitar o corpus.

\subsubsection{Técnica}

O que vem a seguir? é um programa que é executado diretamente do CD-ROM, do pendrive ou do próprio computador quando o mesmo estiver salvo na máquina, sem ser necessário sua instalação. O SE executou nos sistemas operacionais testados: Linux Educacional, Windows XP e Windows 7, incluindo-se no nível 3 da escala de valor dos critérios avaliativos. Não possui instruções claras e objetivas para sua utilização pois, apesar de possuir um item Saiba Mais com informações a respeito das atividades "do lúdico", não há explicação de como utilizar o software.

Quanto à facilidade de acesso a todas as partes que o compõem, contatou-se que em algumas telas é possível voltar à página anterior, porém há um link - recapitular que permite ao leitor ler o texto que até então foi apresentado para ele. Caso haja necessidade de retroceder à página anterior, será necessário reiniciar a atividade. Tendo, então, neste critério, nível 2 de valor.

Não é possível anular a última ação realizada, pois quando o estudante marca uma opção, independentemente se esteja certa ou errada, o SE imediatamente exibe a tela seguinte e emite um feedback referente a sua entrada. Através dos botões, do lápis virtual e da caixa de diálogo, presentes no aplicativo, é possível o discente inserir dados e obter feedbacks de suas entradas. Tal critério alcançou o nível 3.

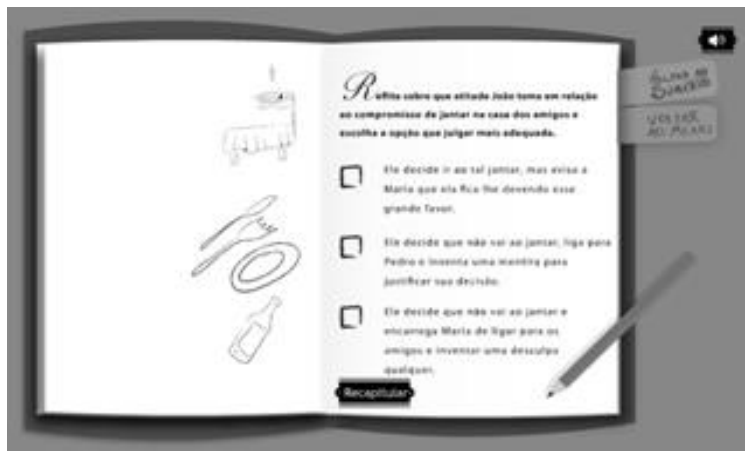

Figura 2: Modelo das atividades propostas no $O$ que vem a seguir?

Na resolução dos exercícios, ao se clicar em uma das alternativas propostas, mesmo estando incorreta, é fornecido ao estudante um feedback informando apenas sobre o erro ou acerto da questão. Esse feedback não é caracterizado por informações que auxiliem o discente na resolução da atividade. Na ocorrência de erros o SE não fornece instruções para que o aluno reavalie sua ação e nem possibilita que ele refaça a atividade. Não há fornecimento da solução após longa persistência do erro já que o trecho que dá continuidade ao texto é exibido após o estudante clicar em umas das alternativas apresentadas (Figura 2). Há presença de ferramentas de interação como links, ícones e botões, no nível 3 da escala de valores, que permitem o usuário interagir e prosseguir com a utilização do SE.

O software apresenta textos de forma similar ao impresso, bem distribuídos na tela, com a presença de apenas um hiperlink que leva a outro texto verbal. A presença desse critério é considerada mediana, nível 2, pois se acredita que as atividades poderiam explorar mais a questão do hipertexto utilizando-o, por exemplo, nas referências, fornecendo uma ligação com o site do autor da narrativa trabalhada para que o discente tenha acesso aos diversos materiais do criador ou mesmo links que apontassem para o próprio software, mas proporcionando atividade mais dinâmica.

Há bastante imagens e animações, correspondendo ao nível 2, principalmente ao iniciar o software. Mas no decorrer do texto as imagens poderiam ser mais atrativas e a animação ser mais presente no aplicativo, já que durante as atividades ela ocorre somente através da imagem de feedback.

No que se refere aos recursos de som e efeito sonoro, obteve-se o nível 2. Durante a utilização do SE é executada uma música instrumental que é alterada a cada texto. A repetição de tais canções pode se tornar irritantes e prejudicar o desempenho do estudante, porém esse recurso pode ser desabilitado com um clique no ícone localizado na parte superior direita da tela. São emitidos também feedbacks sonoros diferenciados para as entradas de dados do usuário, um para o fornecimento de resposta correta e outro para incorreta. As emissões desses efeitos sonoros continuam ativadas mesmo quando se desabilita a opção de execução de música de fundo.

\subsubsection{Pedagógica}

O que vem a seguir? não dispõe de um guia de apoio ao professor, que o oriente na exploração dos conteúdos abordados, portanto o educador terá que desbravar o aplicativo visando o melhor aproveitamento dos conteúdos que serão posteriormente trabalhados com os estudantes. No entanto, há um item Saiba Mais que explica o perfil das atividades, classificadas como lúdicas, e em seguida expõe ao usuário nomes de jogos com o mesmo perfil. Assim, o critério referente aos objetivos pedagógicos pretendidos pelo SE obteve nível 1, considerado fraco ao que se espera nesse aspecto, havendo a necessidade de uma maior explanação a respeito do que se pretende alcançar com o uso do aplicativo, uma vez que foi elaborado pelo MEC em parceria com FNDE, MCT, ÁGORA, 
chamado de Projeto Condigital: Língua Brasil.

No que diz respeito aos fundamentos pedagógicos que o embasam, não há tais explicitações, porém constatou-se que o software apresenta nível 3 referente à coerência de conteúdos e de sua abordagem, de acordo com a proposta pedagógica a que se propôs que é explorar a questão da leitura de textos, produzindo hipóteses e propondo que se descubra o que vem a seguir, mesmo que na maioria das vezes não seja possível se marcar a opção correta nas questões, uma vez que qualquer uma pode ser a correta, dependendo do direcionamento que se queira dar ao enredo.

O trabalho com a leitura e compreensão textual permite que o leitor reflita sobre o texto que está exposto e opine, através de alternativas pré-estabelecidas, sobre os trechos seguintes. No entanto, o texto nem sempre dá pistas suficientes para se encontrar a alternativa que mais se aproxima da ideia do autor do enredo, tendo o leitor que adivinhar a sua continuidade. Assim, as atividades referentes a conteúdos atualizados em relação às teorias de Língua Portuguesa obtiveram nível 2. Obteve-se nível 3 sobre a adequação do conteúdo ao público-alvo, no caso, ao público do fundamental II, mas não há indicação para qual ano desse nível foi destinado o SE.

As atividades propostas se destinam apenas ao ensino da língua materna, não apresentando uma abordagem interdisciplinar. Há somente uma pequena variação, alcançando nível 1 na avaliação relativo ao grau de complexidade de conteúdo nas atividades: ao requerer identificação de informações menos e mais identificáveis e no momento da solicitação da elaboração do final do texto.

O software trabalha com hipóteses, o que desperta o interesse do estudante para descobrir qual a continuação e o desfecho da história. Porém, mesmo sendo um suporte digital, não se percebe presença marcante de recursos motivacionais, que possam manter a atenção do discente. Obteve-se nível 2 neste critério. Percebe-se que se fazem necessários recursos que sejam melhor elaborados, contemplando cores mais atrativas, animações e vídeos.

O aplicativo emite sempre os mesmos feedbacks, um parabenizando o estudante e afirmando que escolheu a opção que corresponde à continuação do texto e outro informando que a opção escolhida não equivale à apropriada e lamenta a escolha. Dessa forma, tais recursos não contemplam características encorajadoras e isentas de carga negativa mediante respostas inadequadas, sendo atribuído o valor 1 . Os feedbacks descritos são verbais, sonoros e animados.

Ao final de cada história é possível visualizar o resultado com o quantitativo de questões propostas e o número de acertos. Esse relatório poderá ser utilizado pelo professor para uma análise ou reflexão sobre o desempenho do estudante, tendo o nível 3 este critério.

O software não favorece a interpretação do usuário sobre seus erros e acertos nem o ajuda a ver suas respostas sob diferentes ângulos, pois, apesar de o SE permitir que o estudante recapitule o texto e reflita sobre ele para que possa marcar uma opção de resposta que dê continuidade à narrativa, não há presença de dicas ou de feedbacks com informações que o ajude a compreender a situação-problema apresentada.

Apesar de não explicitar que sua utilização deva ser em grupo, ou possivelmente entendendo que os alunos estejam utilizando o software individualmente, mas próximos uns dos outros, há um momento em que é proposto aos estudantes discutir com seus colegas sobre o final de uma história, permitindo que eles troquem ideias sem antes conhecer o final proposto pelo autor. Como esse aspecto foi apresentado numa variação considerada fraca, nível 1, entende-se que é necessário promover um ambiente que explore mais questões que integrem os estudantes, que os faça discutir, refletir e tomar decisões favorecidas pelo trabalho em equipe.

\subsubsection{Leitura e compreensão}

No que diz respeito ao ensino da leitura, há presença de atividades com a presença de texto e a partir dele foram elaboradas as questões a serem propostas aos estudantes, e assim tal critério obteve o nível 3. No entanto, mesmo compreendendo o texto, nem sempre é possível acertar a resposta, pois em alguns momentos a narrativa não traz pistas para isso. Há textos não verbais - imagens - que são exibidos juntamente com os fragmentos de textos e, às vezes, antecipam informações que serão descritas nos parágrafos em andamento e que podem ser encaradas como os episódios principais da narrativa. Porém esse elemento não é trabalhado nas questões propostas.

O software permite a leitura e a análise de situações, que se pode chamar de reflexão da leitura, nível 2 no critério, levando o aluno a tentar descobrir fatos a partir da compreensão que teve do fragmento do texto exposto. Apesar disso, verificou-se que as atividades de leitura e compreensão não estimulam a busca de outras leituras sobre a mesma temática, promovendo apenas a leitura sobre a temática dentro do SE.

Não foram encontradas atividades que explorassem a questão do gênero dos textos apresentados, há apenas a menção, em uma das questões, de que o texto se trata de uma crônica. Quanto à identifícação das finalidades dos textos, no sumário solicita-se que o estudante leia o texto, junte as pistas e tente descobrir o que vem a seguir, de acordo com as orientações que aparecem na tela, no entanto, não há identificação das finalidades dos textos. Nas atividades, o leitor vai atuar como um detetive. 
Os textos propostos apresentam características que permitem o leitor identificar os agentes do discurso por meio da interação entre os personagens. Porém essa identificação não é trabalhada nas questões apresentadas. Há a referência dos textos apresentados, no entanto, não foi dedicada nenhuma questão que trate desse aspecto. Não se constatou, ainda, a solicitação de identificação de elementos que indiquem a posição do autor frente aos textos ou autores referidos, somente o estudante é conduzido a direcionar a história de acordo com o que o autor propôs.

Através dos diálogos entre os personagens, pelos verbos de ação, expressões de localização e outros aspectos, pode-se identificar que se trata de uma narração, mas essa questão não foi proposta ao leitor. Para a resolução das questões, às vezes, é necessário ter lido os fragmentos do texto e tê-lo compreendido em sua totalidade, mas não há questionamentos sobre o tema central. $\mathrm{O}$ entendimento adequado das informações será bastante útil para descobrir os trechos seguintes da narração, dessa forma as informações principais ganhariam mais destaque na atividade. No entanto, não há a solicitação de distinção dos tipos de informações: principais e secundárias.

Há apenas uma questão, do total de quatorze, que exige informação explícita, representando o percentual requerido pelo nível 1, e há ocorrência de 10 questões que contemplam informações implícitas, equivalente ao percentual do nível 3 da escala de valores. Verificou-se ainda que 3 questões requerem informações extratexto e que não há atividades que contemplam o trabalho com a gramática da língua. O software trabalha com a capacidade de compreensão do leitor colocando-o em situações onde o seu poder de percepção e imaginação ganhará destaque. Tais aspectos o ajudarão na revelação dos fatos que compõem as narrativas.

Apesar das atividades propostas se destinarem à leitura e compreensão textual a partir de textos narrativos que apresentam diálogos, observou-se que não há questões que explorem os efeitos de sentido do uso de marcas típicas da oralidade. Não há cobrança quanto à avaliação da adequação de determinados usos dialetais e de registro às condições da situação de interação, apesar de haver registro de falas de personagens e expressões utilizadas da linguagem cotidiana. Também não há requisição de elementos responsáveis pelos efeitos de humor e ironia nos textos apresentados, mesmo havendo a possibilidade de explorá-los, uma vez que se tratam de um conto e uma crônica que apresentam humor. Além disso, não há ocorrência de identificação de sentidos de palavras ou expressões do texto, apesar de aparecerem expressões que mereceriam atenção específica.

Contatou-se ainda que as atividades não proporcionam o reconhecimento dos efeitos de sentido de palavras ou expressões, não obstante o leitor ter que interpretar determinadas situações, a fim de reconhecer as possíveis direções dos acontecimentos.

Nas atividades do software cada fragmento é tido como determinante para coerência e coesão do texto proposto. A correta ligação entre esses fragmentos proporcionará a compreensão geral do texto, a continuidade do enredo e o desfecho da história. Mas os aspectos referentes às relações existentes entre partes do texto obtiveram o nível 1, uma vez que nos exercícios não há a exigência específica deste item.

Verificou-se que as atividades de leitura e compreensão do SE não proporcionam o reconhecimento, entre partes de textos, das relações textuais indicadas por meio de expressões conectivas. Além disso, as questões propostas levam o estudante a fazer reflexões sobre os fatos narrados a fim de que ele possa criar, em seu imaginário, o perfil de cada personagem e com isso arquitetar como reagirão a determinadas situações que, por conseguinte, conduzirão ao desfecho da história, contudo não há reflexões linguísticas neste sentido.

Para uma melhor visualização dos resultados das análises expostas acima, na Tabela 1 é possível ver o resultado quantitativo obtido do software em questão.

\begin{tabular}{|c|c|c|c|c|c|c|}
\hline \multicolumn{7}{|c|}{ Resultado Quantitativo } \\
\hline Níveis & 0 & 1 & 2 & 3 & NA & \multirow[b]{2}{*}{$\begin{array}{l}\mathrm{T} \\
\mathrm{O} \\
\mathrm{T} \\
\mathrm{A} \\
\mathrm{L}\end{array}$} \\
\hline Categoria & 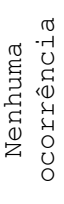 & $\begin{array}{l}\text { do } \\
\text { n } \\
m \\
1 \\
010 \\
+1\end{array}$ & $\begin{array}{c}10 \\
0 \\
1 \\
1 \\
10 \\
6 \\
m \\
m\end{array}$ & 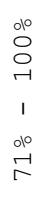 & $\begin{array}{cc}0 & \sigma \\
0 & 0 \\
0 & -r \\
0 & -1 \\
20 & 0 \\
z & 0\end{array}$ & \\
\hline Técnica & 6 & 0 & 4 & 3 & 1 & 14 \\
\hline Pedagógica & 4 & 4 & 2 & 4 & 0 & 14 \\
\hline Específica & 16 & 2 & 1 & 2 & 1 & 22 \\
\hline Conceitos & 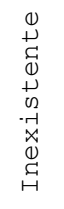 & $\begin{array}{l}0 \\
0 \\
\pi \\
4 \\
\text { I }\end{array}$ & $\begin{array}{c}\xi \\
\text { Ð } \\
\text { ๓ }\end{array}$ & \begin{tabular}{l}
0 \\
\multirow{E}{*}{} \\
-1 \\
+ \\
0
\end{tabular} & 1 & \\
\hline
\end{tabular}

Tabela 1: Resultado quantitativo - O que vem a seguir?

\subsection{Educandus 2010}

O CD-ROM Educandus 2010 é indicado ao Ensino Fundamental II e contempla as disciplinas: Ciências, Geografia, História, Matemática e Português. Para iniciar as atividades, o programa deverá ser instalado a partir de uma senha, mas para execução do software o CD deverá permanecer no drive. 
A página referente à disciplina de Língua Portuguesa (Figura 3) contém atividades distribuídas em quatro partes, cada uma correspondendo a um ano escolar. Para esta pesquisa foram escolhidos a parte $3\left(8^{\circ}\right.$ ano) e dois conjuntos de atividades para análise dos exercícios de leitura e compreensão textual: "Coesão e coerência; parágrafo e texto" e "Termos da oração e análise sintática".

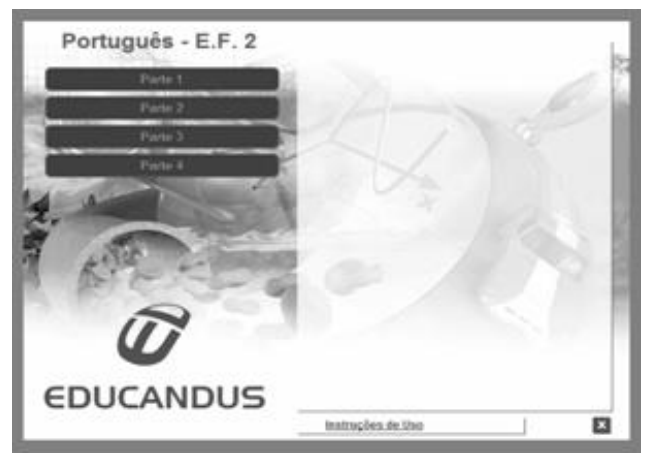

Figura 3: Tela Inicial do Educandus 2010 - Português

\subsubsection{Técnica}

O software apresenta instruções bem detalhadas e com demonstrações claras, mas o layout (interface) das demonstrações não correspondem ao aplicativo em análise, nem ao apresentado nas outras disciplinas por ele contempladas (Figura 4), ou seja, pouco ou quase nada do que é demonstrado nas instruções são aplicáveis ao software analisado. Assim, esse critério recebeu valor 1 na escala.

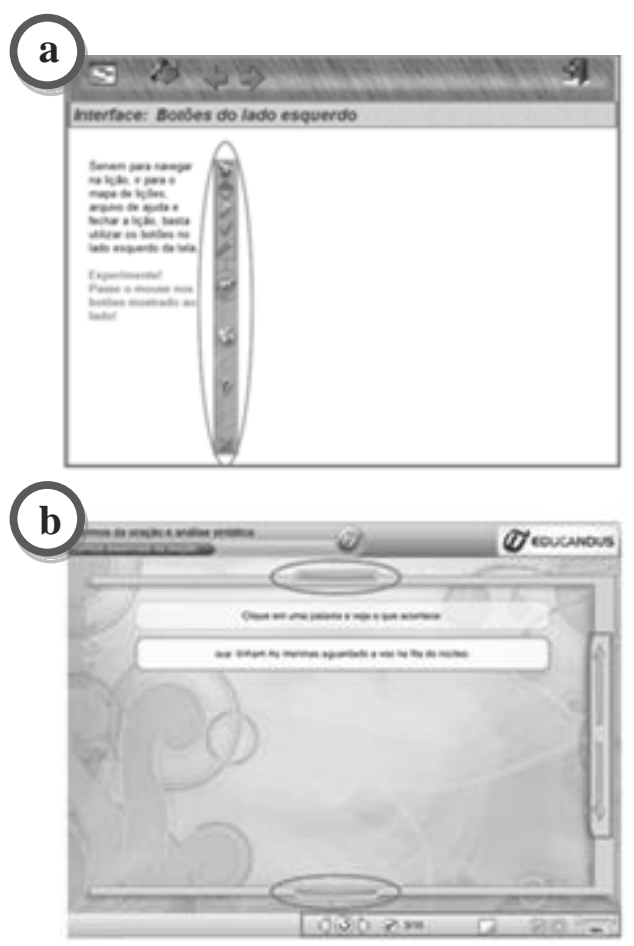

Figura 4: . Interface do Educandus 2010:

a) demonstrada nas instruções de uso; b) encontrada no software.

O aplicativo não executou no ambiente Linux, porém rodou nos sistemas operacionais Windows XP e Windows 7, no entanto, no Windows 7 com 64 bits não é possível rodar. Quanto à instalação, há um documento, entre os arquivos que compõem o CD-ROM, com instruções a respeito da operação supracitada. Além disso, a tela de instalação do SE é simples e de fácil acesso, contemplando um nível 3 de qualidade.

Há botões, em um percentual referente ao nível 3, que permitem avançar para a próxima página ou retroceder para a anterior; há um ícone com um canguru que permite o estudante pular para a página que desejar e ainda um botão que possibilita reiniciar a atividade. Há também o mapa de acesso que contém todas as lições do SE.

Existem feedbacks significativos, em nível 2, pois há resposta em diversos procedimentos do usuário e esse recurso é executado quando o estudante clica nos botões presentes no SE. Há um percentual significativo, nível 3, referente à possibilidade de avançar ou retroceder a uma página que faça parte de um conjunto de atividades de cada lição sem que haja alteração nas entradas de dados do estudante. Porém se ele avançar para o conjunto seguinte, quando retornar ao anterior suas ações terão sido encerradas, mas ele poderá refazê-las. Também é possível reiniciar uma atividade.

Com relação à anulação da última ação realizada, esta só é aceita quando a atividade propõe assinalar verdadeiro ou falso ou ainda quando a questão pede que se insira informações, em uma caixa de texto, referentes ao conteúdo trabalhado na lição. Quando se trata de questões de múltiplas escolhas, é emitido um feedback a cada entrada de dado do usuário, não permitindo a anulação de sua última ação, o que leva o critério descrito a obter nível 1 nas atividades.

Há expressivo percentual, nível 3, referente à possibilidade de refazer os exercícios propostos até que as respostas fornecidas sejam adequadas àquelas julgadas corretas pelo SE. Em alguns feedbacks são fornecidas dicas para resolução da atividade. Há sinalização de erro ou acerto das questões por meio dos feedbacks que, em sua minoria, fornecem informações que ajudarão o estudante na resolução do exercício proposto. Nos exercícios que se apresentam na forma de sentenças, de assinalar verdadeira ou falsa, há o fornecimento do gabarito após a terceira tentativa. A cada ação para resolução da atividade, o usuário deverá clicar no botão Avaliar para submeter sua resposta à correção. Há também fornecimento da solução nas atividades onde as respostas deverão ser inseridas numa caixa de texto para avaliação pelo software. Neste caso, a resposta correta também é fornecida após três erros seguidos. Nas outras atividades não há fornecimen- 
to da solução.

Há a presença marcante, nível 3, de ferramentas de interação como links, ícones e botões que permitem uma boa interação estudante x SE. Os textos são bem distribuídos facilitando, assim, a sua leitura. Os hipertextos estão presentes, por exemplo, na forma de Saiba Mais com informações referentes ao autor, a determinado gênero textual, entre outros aspectos. O critério descrito obteve valor 3 .

O software explora as animações, em nível 3, através de episódios de uma narrativa. A utilização desses recursos é pertinente ao que está sendo trabalhado e pode manter ou despertar o interesse do estudante na utilização do aplicativo e facilitar a aprendizagem dos conteúdos trabalhados. Há ausência de recursos de som nos diálogos das atividades, o que contradiz a expectativa do usuário que espera que tenha som, por causa de todas as características apresentadas pelo SE.

\subsubsection{Pedagógica}

O Educandus 2010 - Português não possui guia de apoio ao professor, portanto, é necessário que o docente faça um reconhecimento do material para planejamento de ações de uso com os estudantes. Além disso, não há presença de informações que explicitem os fundamentos pedagógicos adotados durante seu desenvolvimento, apesar de afirmar que é um recurso embasado em avançados métodos pedagógicos para o auxílio do aprendizado. Constatou-se também que ele não explicita seus objetivos pedagógicos: ao clicar em um dos hiperlinks no mapa de acesso às lições, o estudante é direcionado à atividade escolhida sem, contudo, ser apresentado aos objetivos pedagógicos pretendidos pela lição.

Pode-se afirmar que há somente uma pequena variação, nível 1 na escala de valores, de conteúdos atualizados em relação às recentes teorias da área, sendo a maioria das abordagens trabalho com conteúdos da gramática tradicional. De uma maneira geral, pode-se dizer que os conteúdos trabalhados não são atuais e adequados ao público-alvo, pois precisaria que se adequasse ao novo currículo da disciplina, conforme proposta de documentos oficiais sobre o ensino de língua. Esse critério obteve valor 1 .

Verificou-se que o aplicativo trabalha apenas com conteúdos de Língua Portuguesa, nível 3 na escala, na parte do software que corresponde a esta disciplina, não apresentando abordagem interdisciplinar, mesmo o software contemplando outras disciplinas. Com relação aos diferentes graus de complexidade do conteúdo, percebeuse que há, em nível 2, a identificação de elementos linguísticos e discursivos que requer do leitor um grau menor e maior de raciocínio.
Quanto aos recursos motivacionais, há animações em geral e personagem animado exibido junto à mensagem de feedback de entrada de dados que podem ser facilmente explorados pelos botões inseridos na área de trabalho, presentes em nível 2. Há ainda presença de som que pode prender a atenção do usuário. Porém há ausência desse recurso para os diálogos, o que se esperava que tivesse, já que se trata de imagem semelhante à projeção de um pequeno filme, onde foi explorada somente a escrita. Outro aspecto que precisaria melhorar é que há muitas repetições de estrutura de resposta de atividades, o que pode ser cansativo para o usuário.

Os feedbacks, presentes num nível 3, informam se a resposta está correta ou não, mas existem também os explicativos que orientam o discente na resolução da atividade proposta, ao responder inadequadamente. Sempre há retorno às respostas do usuário, em nível 2. Há favorecimento da interpretação sobre seus erros e acertos. Quanto ao desempenho do estudante, este não é registrado pelo SE.

Nas instruções de uso há indicação de que as "Aulas Multimídia" podem ser utilizadas em bibliotecas, sendo que neste espaço a utilização do material pode ocorrer de maneira individual ou em grupo permitindo uma grande interação com livros, internet, etc. Mas, não se percebem aspectos específicos para utilização do SE em atividades grupais, situação esta, que poderá ser revertida de acordo com o direcionamento dado pelo professor.

\subsubsection{Leitura e compreensão}

No que tange à parte específica, verificou-se que o software propõe, num percentual correspondente ao nível 2 , exercícios que se constroem a partir dos textos apresentados que deverão ser lidos e interpretados. No entanto, há textos que aparecem como pretexto para questões de gramática tradicional. O software também permite identificar, em nível 1, sentidos ou informações em textos não verbais, pois apresenta uma matéria em que uma das letras de uma palavra do título recebe um tratamento visual diferenciado e a atividade solicita que se faça a relação entre esse tratamento visual e o conteúdo da matéria. É possível perceber a reflexão crítica a partir dos textos apresentados e de algumas das questões sobre eles, mas esse aspecto é contemplado apenas num percentual em nível 1. As atividades propostas não estimulam a busca de outras leituras sobre a mesma temática, apenas incentivam a releitura de textos que estão no próprio SE.

Duas atividades apenas fazem menção ao gênero textual cartão-postal, nível 1, e é trabalhada a questão do remetente, destinatário e a relação de sentido entre os fatos narrados no texto que está inserido no gênero mencionado. Há também o reconhecimento de finalidades pretendidas para o texto, com atribuição de valor 1 , ex- 
plorado através do trabalho com o cartão-postal. Observou-se um considerável número de atividades, em nível 2 , que proporcionam a identificação de elementos indicadores das condições do locutor e do interlocutor do texto, pois trabalham com a compreensão da intencionalidade discursiva onde se precisa levar em consideração a situação comunicativa (quem fala, como fala, em que contexto, etc.). Contudo, os exercícios não proporcionam a identificação de referências ou remissões a outros textos ou a outros autores, uma vez que há apenas referências aos textos trabalhados no próprio software. Além disso, não há exploração de identificação de elementos que indiquem a posição do autor frente aos textos ou autores referidos.

Quanto ao reconhecimento de característica do tipo textual, não há cobrança nesse sentido, mas há um exercício que explora as características de um cartão-postal, como mencionado, tais como remetente, destinatário, assunto, finalidade do cartão e informações no verso do postal, tratando-o como tipo textual.

As atividades do aplicativo não distinguem informações principais e secundárias e são focadas no enredo das narrativas e na gramática normativa. Das 53 questões, 13 são de reconhecimentos de informações explícitas nos textos, correspondendo ao percentual do nível 1. No mesmo nível, há o trabalho com a intencionalidade onde se faz necessário perceber a intenção de quem fala, identificando o que está implícito no que é dito ou na situação de comunicação. Das 53 questões, 13 são para deduzir, inferir sobre informações nos textos e 1 questão extratexto, que não tem nenhuma correspondência com o texto.

Há solicitação de reconhecimento de efeitos de sentido do uso de marcas típicas da oralidade, em nível 1, aspecto este trabalhado com piadas, e não há menção sobre adequação dialetal. Percebe-se ainda a possibilidade de reconhecimento de elementos responsáveis pelos efeitos de humor e ironia no texto. O humor acontece graças ao duplo sentido de alguns verbos: ter, sentir e achar. Esse critério recebeu valor 1 na escala de valores.

Há a presença de falas de personagens, porém não são trabalhados aspectos referentes a essas falas. Apresentam as definições de liberdade e hierarquia e há a exploração desses sentidos nas questões, representada no nível 1. Há ainda trabalho com as conjunções e de algumas expressões que vão produzir efeitos de sentidos. Tais aspectos possuem o mesmo percentual do critério anterior.

Houve registro de exercícios, em nível 1, que estabelecem relações entre partes de um texto, identificando repetições, substituições ou associações que contribuem para sua coesão e coerência, propondo, por exemplo, que se construa a resposta a partir do sentido criado pelo texto e salienta que na língua portuguesa é necessário obedecer a uma hierarquia e que algumas palavras dependem de outras para construir significados. Constatou-se também a presença de abordagens sobre as conjunções e outros elementos conectivos, cujo percentual foi em nível 1.

As atividades permitem o reconhecimento, em nível 1 , entre partes de textos, as relações textuais indicadas por meio de expressões conectivas, para promoção da coesão e coerência do texto ou fragmento textual apresentado. E a maior parte do trabalho com a estrutura da língua é de maneira descontextualizada e com uma abordagem tradicional da língua. Das 53 questões, 26 são de abordagem da estrutura da língua, tendo a contextualização um percentual equivale apenas ao nível 1.

Na Tabela 2 é possível conferir o resultado quantitativo obtido após uma avaliação criteriosa do software Educandus 2010.

\begin{tabular}{|c|c|c|c|c|c|c|}
\hline \multicolumn{7}{|c|}{ Resultado Quantitativo } \\
\hline Níveis & 0 & 1 & 2 & 3 & $\mathrm{NA}$ & \multirow[b]{2}{*}{$\begin{array}{l}\mathrm{T} \\
\mathrm{O} \\
\mathrm{T} \\
\mathrm{A} \\
\mathrm{L}\end{array}$} \\
\hline Categorias & 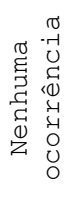 & 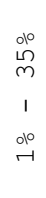 & 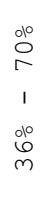 & 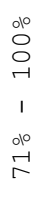 & $\begin{array}{cc}0 & \sigma \\
0 & 0 \\
0 & -r \\
0 & -r \\
2 \pi & 0 \\
2 & 0 \\
z\end{array}$ & \\
\hline Técnica & 1 & 3 & 3 & 7 & 0 & 14 \\
\hline Pedagógica & 6 & 2 & 3 & 2 & 1 & 14 \\
\hline Específica & 6 & 14 & 2 & 0 & 0 & 22 \\
\hline Conceitos & 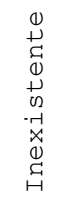 & $\begin{array}{l}0 \\
0 \\
0 \\
0 \\
0 \\
\text { y }\end{array}$ & $\begin{array}{l}\text { D̆ } \\
\text { ๓ }\end{array}$ & 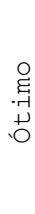 & 1 & \\
\hline
\end{tabular}

Tabela 2: Resultado quantitativo - Educandus 2010

\section{Considerações finais}

Nesta seção é importante deixar claro que para afirmar que os softwares têm boa potencialidade de uso na prática pedagógica, aqueles aqui analisados e os que possam vir a ser analisados a partir dos critérios estabelecidos por Silva et al. [13], é preciso que eles contemplem a maioria dos critérios nos níveis 2 e 3 em cada categoria, o que corresponde ao percentual de $36 \%$ a $100 \%$ de ocorrência da maioria dos critérios. Se a representação da maioria das ocorrências se encaixa entre 0 e $35 \%$ em todas as categorias, pode-se afirmar que os softwares têm uma tendência de não promover um bom trabalho pedagógico. $\mathrm{E}$ se esse intervalo de percentual acontecer em uma ou duas das categorias, pode-se afirmar que os softwares estarão deficientes nesses aspectos, podendo prejudicar o desempenho do estudante na utilização do SE ou na aquisição do conteúdo específico, dependendo do 
que se constatou como falho. No entanto, em ambos os casos pode comprometer os processos de ensino e aprendizagem também.

No software $O$ que vem a seguir?, na categoria técnica, constatou-se a ausência das instruções de utilização, possibilidade de interrupção, retomada e reiniciação de atividade a qualquer instante, anulação da última ação realizada, de refazer exercícios, fornecimento de explicações para correção de atividade e de solução após longa persistência do erro. Houve registro de três ocorrências no nível 3: compatibilidade com diferentes sistemas operacionais, emissão de feedback de todas as entradas do aluno e presença de ferramentas de interação como links, ícones e botões. Por não ser necessária a instalação do software para seu uso, o critério referente a esse item não foi aplicado. Nesta categoria, considera-se que o software apresenta uma potencialidade que possa permitir um trabalho pedagógico de qualidade, pois a maioria dos critérios foi contemplada a contento.

No tocante aos critérios pedagógicos, registrou-se um elevado quantitativo de ocorrências nos níveis 0 e 1 , correspondendo aos aspectos referentes ao instrumento para ajuda docente na utilização do aplicativo, à presença de informações a respeito dos fundamentos e objetivos pedagógicos, à abordagem interdisciplinar, ao grau de complexidade de conteúdo, ao feedback encorajador mediante respostas inadequadas, ao favorecimento à interpretação sobre os erros e acertos e ao trabalho em grupo. Nesse sentido, entende-se que a ausência de tais aspectos contribui para a má qualidade do software nessa categoria, a qual necessitaria vislumbrá-los, se não em um nível alto, mas em um nível mediano. Já o nível 3, foi contemplado com os critérios relativos aos conteúdos e às abordagens coerentes à proposta apresentada, ao conteúdo adequado ao público alvo, à ênfase em uma disciplina e ao registro de desempenho do aluno. Tais aspectos estão presentes em quantidade e qualidade adequados, contribuindo positivamente para a avaliação do software. Esta categoria não apresenta a maioria dos critérios em um nível de ocorrência esperado para propiciar um bom trabalho pedagógico, podendo prejudicar os processos de ensino e aprendizagem.

No que se refere às atividades com a leitura, percebeu-se que do total de 22 critérios, 16 foram registrados em nível zero e duas ocorrências em nível 1 , tornando o software pouco viável para desenvolver conhecimento na área em questão, destacando-se com o conceito ótimo apenas em 2 critérios: na apresentação de textos verbais em boa quantidade, na depreensão de informações implícitas. No entanto, vale salientar que esse software apresenta uma característica lúdica e não pedagógica. Não há realmente abordagens de conteúdos específicos dos componentes curriculares para que ele seja considerado como um software elaborado para o fim pedagógico, mas para prazer e diversão do usuário, apesar de ter sido elaborado pelo MEC e fazer parte do Projeto Condigital: Língua Brasil.

No Educandus 2010 - Português apenas o critério referente à presença de efeito sonoro foi registrado inexistente na categoria técnica. Houve três ocorrências com conceito fraco: presença de instruções para uso, compatibilidade com diferentes sistemas operacionais e possibilidade de anulação da última ação realizada. Registrou-se significativa presença de critérios no nível 3, sete ocorrências: facilidade de instalação e desinstalação, facilidade de acesso a todas as partes do software, possibilidade de interrupção, de retomada e de reinicialização de uma tarefa a qualquer instante, orientação e possibilidade de refazer exercícios quando há ocorrência de erros na resolução, presença de ferramentas de interação, de textos e de hipertextos, de imagens e animações pertinentes ao contexto. Neste software, verifica-se que a categoria técnica se apresenta em boas condições de proporcionar ao usuário facilidade e dinamismo no seu uso.

No que diz respeito à categoria pedagógica, não houve a presença de guia de apoio pedagógico, de explicitação dos fundamentos e objetivos pedagógicos, abordagem interdisciplinar, registro de desempenho do estudante e favorecimento do trabalho em grupo. Os critérios referentes aos conteúdos atualizados e adequados ao público-alvo foram considerados fracos, uma vez que a maioria das abordagens consiste em conteúdos da gramática tradicional, necessitando, portanto, de uma adequação ao novo currículo da disciplina que considera "as esferas comunicativas, os gêneros textuais para estudo, os seus suportes, as circunstâncias de uso e os interactantes" [11]. No nível 3, dois critérios foram registrados: ênfase em uma disciplina específica e emissão de feedback encorajador mediante respostas inadequadas. Nesta categoria, verifica-se que o software não oferece bons subsídios para que a prática pedagógica possa ser viabilizada a contento, podendo interferir na aquisição do conhecimento.

$\mathrm{Na}$ parte específica, houve seis ocorrências no nível zero: estímulo à busca de outras leituras sobre a mesma temática, identificação de referências ou remissões a outros textos, identificação de elementos que indiquem a posição do autor frente aos textos, possibilidade de reconhecimento do tipo textual, distinção de informações principais e secundárias e adequação dos usos dialetais. Além disso, houve quatorze ocorrências no nível 1, relacionadas à identificação de sentidos ou informações não verbais, à questão da reflexão crítica da leitura, ao reconhecimento de característica do gênero textual e de finalidades do texto, à identificação do tema central, à localização de informações implícitas e explícitas, ao reconhecimento de efeitos de sentido do uso de marcas da oralidade e às reflexões linguísticas contextualizadas. Apenas 
os aspectos dedicados à presença de textos verbais e de identificação de elementos indicadores das condições do locutor e do interlocutor do texto foram considerados bons, não havendo nenhuma ocorrência no nível 3. Constata-se, então, que essa categoria não apresenta potencialidade para desenvolver habilidades leitoras no usuário, pois os aspectos relevantes para esse fim, não são abordados a contento, mesmo com a grande presença de texto.

Vale ressaltar que mesmo que um software contemple todos os critérios propostos por Silva et al. [13], não implica que isso seja suficiente para considerá-lo eficiente na prática pedagógica, pois é somado à maneira como ele será utilizado pelos educadores em sala de aula que permitirá a obtenção de resultados satisfatórios.

\section{Agradecimentos}

As autoras agradecem ao Programa de Fortalecimento Acadêmico da Universidade de Pernambuco pelo apoio financeiro a este projeto.

\section{Referências}

[1] A. P. R. Atayde. Metodologia de Avaliação de Qualidade de Software Educacional Infantil MAQSEI. Dissertação de Mestrado, UFMG, 2003.

[2] Brasil. Secretaria de Educação Fundamental. Parâmetros curriculares nacionais: terceiro e quarto ciclos do ensino fundamental: língua portuguesa. Secretaria de Educação Fundamental. - Brasília: MEC/SEF, 1998.

[3] R. J. Dall'asta. A transposição didática no software educacional. UPF, Passo Fundo, 2004.

[4] M. T. A. Freitas. Descobrindo novas formas de leitura e escrita. In: R. Rojo (org.). A prática de linguagem em sala de aula: praticando os PCN's, Mercado de Letras, Campinas, 2008.

[5] Â. Kleiman. Texto e leitor: aspectos cognitivos da leitura. Pontes, Campinas, 2002.

[6] A. C. Lobo-Sousa;, J. C. Araújo; R. C. Pinheiro. Letramentos que emergem da hipertextualidade. In: J. C. Araújo; M. Dieb (orgs.). Letramentos na Web: gêneros, interação e ensino. Edições UFC, Fortaleza, 2009.

[7] C. C. Oliveira; J. W.; M. M. Costa. Ambientes informatizados de aprendizagem: produção e avaliação de software educativo. Papirus, Campinas, 2001.
Compreensão de Hipertextos. In: J. C. Araújo; B. Biasi-Rodrigues. Interação na Internet: Novas formas de usar a linguagem. Editora Lucerna, Rio de Janeiro 2005.

[9] C. F. Santos; M. Mendonça; M. C. B. Cavalcanti (orgs.). Diversidade textual: os gêneros na sala de aula. Autêntica, Belo Horizonte, 2006.

[10] B. Schneuwly; J. Dolz. Os gêneros escolares: das práticas de linguagem aos objetos de ensino. In: R. Rojo; G. S. Cordeiro (orgs.). Gêneros orais e escritos na escola. Mercado das letras, Campinas, 2004.

[11] A. C. B. Silva. Os gêneros textuais em um novo suporte: softwares educativos. In: Anais do $\mathrm{V}$ Simpósio Internacional de Estudos de Gêneros Textuais - V SIGET. Caxias do Sul - RS: UCS, 2009.

[12] E. T. Silva. A produção da leitura na escola: Pesquisa x Propostas. $2^{\mathrm{a}}$ ed. Editora Átira, São Paulo, 2002.

[13] A. C. B. Silva; R. S. França; W. C. Silva. Uma proposição de critérios para avaliação de softwares educativos de Língua Portuguesa. In: XXII Simpósio Brasileiro de Informática na Educação, Aracaju, p. 1104-1107, 2011.

[14] A. C. B. da Silva. Softwares Educativos: Critérios de Avaliação a partir dos Discursos da Interface, da Esfera Comunicativa e do Objeto de Ensino. Tese de Doutorado, UFPE, 2012.

[15] I. Snyder. Ame-os ou deixe-os: navegando no panorama de letramentos em tempos digitais. In: J. C. Araújo; M. Dieb (orgs.). Letramentos na Web: gêneros, interação e ensino. Edições UFC, Fortaleza, 2009.

[16] M. Soares. Novas práticas de leitura e escrita: letramento na cibercultura. In: Educ. Soc., Campinas, vol. 23, n. 81, p. 143-160, dez. 2002.

[17] V. M. C. Tavares. As novas exigências do letramento e a construção de um ambiente propício ao ensino da leitura. In: J. C. Araújo; M. Dieb (orgs.). Letramentos na Web: gêneros, interação e ensino. Edições UFC, Fortaleza, 2009.

[18] F. M. S. Vieira. Avaliação de software educativo: reflexões para uma análise criteriosa, 2000. Disponível em: http://www.proinfo.gov.br/prf_txtie.htm. Acesso em: 05/02/2010.

[19] A. S. Zardini. Software educativo para ensino de inglês: análise e considerações sobre seu uso. Dissertação de Mestrado, CEFET/MG, 2009. 